\title{
CCR5 Genotypes and Progression to HIV Disease in Perinatally Infected Children
}

\author{
Daniela Souza Araújo de Angelis ${ }^{1}$, Wilton Santos Freire ${ }^{1}$, Cláudio Sergio Pannuti ${ }^{1}$, \\ Regina Célia de Menezes Succi ${ }^{2}$ and Daisy Maria Machado ${ }^{1,2}$ \\ ${ }^{1}$ Institute of Tropical Medicine of São Paulo, LIM52-HCFMUSP; ${ }^{2}$ Federal University of São Paulo, UNIFESP; São Paulo, SP, Brazil
}

\begin{abstract}
The CCR5 molecule, a chemokine receptor, is the most important co-receptor for macrophage-tropic HIV-1. A 32-bp deletion in the gene encoding CCR5 (CCR5-del32) confers nearly complete resistance to HIV-1 infection in homozygotes, and slows the rate of progression to AIDS in heterozygous adults. The aim of this study was to describe the CCR5 genotypes and the characteristics of HIV disease progression in perinatally infected children. From a total of 51 children analyzed for the CCR5-del32 mutation, 18 (35\%) were considered to be rapid progressors, 28 (55\%) were moderate progressors and $5(10 \%)$ were slow progressors. A portion of the CCR5 gene was amplified by PCR from genomic DNA followed by agarose gel electrophoresis. Forty-nine children (96\%) carried the homozygous wild type genotype for CCR5 while 2 (4\%) carried the heterozygous wt/del32 genotype. In the population studied, the CCR5 genotype was unable to account for the differences in pattern of the disease progression among the three groups (rapid, moderate and slow progressors), and the allele frequency of CCR5-del32 was too low to allow statistical comparisons with adequate resolving power. Studies on larger populations may help to further elucidate the role of this allele and other host factors in the regulation of HIV-1 pathogenesis in children.

Key-Words: HIV-1, CCR5 co-receptor, HIV disease progression, perinatally infected children.
\end{abstract}

From the late nineties onwards, expressive advances in healthcare practices concerning HIV-positive children have led to changes in the clinical course of the illness, resulting in lower morbidity and mortality [1].

HIV-1 infection in children takes a variable course, causing early symptoms in approximately $20 \%$ (rapid progression) [2] . Most children show moderate progression of the illness, and a small group remains asymptomatic for many years [3]. Several factors contribute to this scenario, mainly linked to viral and host characteristics. Regarding host factors, the pertinent literature emphasizes the role of the CCR5 gene that encodes a cell-surface, chemokine-receptor molecule which serves as a co-receptor for macrophage-tropic strains of HIV-1 [4,5].

Homozygosity for the 32-bp deletion (del32/del32) in the CCR5 gene confers a certain degree of resistance to HIV-1 infection, while heterozygosity (del32/wt) slows the rate of progression to AIDS in adults [6,7].

To better understand the role of the del32 allele in HIV-1 disease progression in children, in the present study, we evaluated the genotypes of the CCR5 co-receptor in children exhibiting different time courses of progression to AIDS.

\section{Materials and Methods}

Study Population

The present study was conducted on HIV-infected children attended at the Federal University of São Paulo (SP, Brazil),

Received on 15 August 2006; revised 7 February 2007.

Address for correspondence: Dr. Daniela Souza Araújo de Angelis. Laboratório de Virologia (LIMHC-52), Instituto de Medicina Tropical de São Paulo. Av. Dr. Enéas de Carvalho Aguiar, 470. Zip code: 05403000 São Paulo (SP), Brazil. Phone: 55-11-3066-7012. Fax: 55-113063-2659. E-mail: angelis@usp.br. This study was supported by Fundação de Amparo à Pesquisa do Estado de São Paulo (FAPESP) Grant 02/08682-9.

The Brazilian Journal of Infectious Diseases

2007;11(2):196-198. (C) 2007 by The Brazilian Journal of Infectious Diseases and Contexto Publishing. All rights reserved. enrolled from November 2001 to October 2003, during routine clinical visits, which took place approximately every 2 months. Signed, informed consent was obtained from the parents or guardians of all 51 children enrolled in the study. The present investigation and the protocols comply with the Research Ethics Committee of Federal University of São Paulo.

The demographic characteristics of the studied population are provided in Table 1. All children enrolled had acquired the infection by vertical transmission of HIV, and were analyzed for CCR5 genotypes, $\mathrm{CD}_{4}$ nadir counts, immunological and clinical categories and pattern of progression of HIV disease. The revised CDC classification [8] was used to define clinical categories and the degrees of immunosupression based on age-specific $\mathrm{CD}_{4}$ T-lymphocyte counts. Children were considered to be either rapid, moderate or slow progressors when they exhibited clinical signs and symptoms of the disease, or signs of immunodeficiency, within the first two years of life, between 2-8 years, and after 8 years of age, respectively.

\section{DNA Samples}

DNA samples were obtained from PBMC using 4\% saponin and the QIAamp Blood kit (QIAGENInc, Santa Clarita, C.A., USA), according to the manufacturers.

\section{CCR5 Genotyping}

A portion of the CCR5 gene was amplified by PCR utilizing primers that flank the 32-bp deletion (P1(2975), 5'CAAAAAGAAGGTCTTCATTACACC - $3^{\prime}$ and P2(2976), 5'-CCTGTGCCTCTTCTTCTCATTTCG -3')[9]. Wild-type and deleted fragments of 189 and $157 \mathrm{bp}$, respectively, were generated. The presence of both fragments was considered to represent heterozygosity (wt/del32). The PCR reaction mixture contained $0.25 \mathrm{mM}$ DNTPs, 20 pmol of each primer, and 0.5 Unit of Taq polymerase in $1 \mathrm{x}$ reaction buffer (Invitrogen). Each PCR amplification consisted of 40 cycles 
as follows: the first 5 cycles at $94^{\circ} \mathrm{C}$ for $1 \mathrm{~min}, 55^{\circ} \mathrm{C}$ for $1 \mathrm{~min}$ and $72^{\circ} \mathrm{C}$ for $1.5 \mathrm{~min}$; 35 cycles at $94^{\circ} \mathrm{C}$ for $30 \mathrm{~s}, 60^{\circ} \mathrm{C}$ for $30 \mathrm{~s}$, and $72^{\circ} \mathrm{C}$ for $45 \mathrm{~s}$, were carried out in a MasterCycler thermal cycler (Eppendorf).

A $10 \mu \mathrm{L}$ aliquot of each $25 \mu \mathrm{L}$ PCR reaction mixture was run on a $2.5 \%$ agarose gel electrophoresis and the appropriately sized products were visualized under UV illumination after staining with ethidium bromide $(1 \mu \mathrm{g} / \mathrm{mL})$. Molecular size marker is indicated at right in basepairs (Figure 1).

\section{Results}

Forty-nine (96\%) of the 51 infected children were homozygous for the wild-type CCR5 genotype (wt/wt), and 2 (4\%) were heterozygous for the del32 genotype (wt/del32). We found no homozygosity for the mutated allele (del32/del32) (Table 2). Between the two heterozygotes, one was a moderately symptomatic rapid progressor and the other was a severely symptomatic moderate progressor. The rapid progressor was a three year-old boy who showed the first symptoms at 7 months of age and the moderate progressor was a seven year-old boy who showed the first symptoms at 3 years of age. Most children showed a pattern of moderate progression ( $n=28 ; 55 \%) ; 18$ children (35\%) were rapid progressors, and 5 (10\%) were slow progressors.

There were no significant differences among the slow, moderate and rapid progressors in terms of their CCR5 genotypes or in terms of age, $\mathrm{CD}_{4}$ nadir values and immunological classification. More children classified as rapid progressors had reached clinical category $C(n=9 ; p<0.05)$, compared to moderate and slow progressors.

\section{Discussion}

Several large studies of the effects of CCR5 genotypes on HIV disease progression have been undertaken in adults $[6,10,11]$; however, less data are available for children $[12,13]$.

There is a high frequency of the CCR5-del32 allele genotype among Caucasians from North America and Europe, 1\% of them possessing the homozygous allele, while 10 and $20 \%$, respectively, exhibit the heterozygous allele [14,15]. The frequency of the heterozygous allele among Afro-Americans is $6 \%$, with $7 \%$ among Hispanics, $13 \%$ among native Americans and $0.6 \%$ among Asians [16]. The highest recorded allele frequency is $20.93 \%$, found in the Ashkenazi Jews, known to be highly endogamous [17].

The results of the present study showed that the normal CCR5 genotype was the most frequent among our outpatient HIV-1 children.

The prevalence of the heterozygous allele in this group of children of different ethnic origins was 4\%, comparable to the findings for various studies in Brazilian adults (5\% in blood donors [18], and 5.1\% in patients with falciform anemia [19]). Silva et al. reported a $6.5 \%$ incidence of the heterozygous genotype among blood donors from São Paulo city, Brazil.

Many studies have been performed to evaluate whether heterozygosity of the CCR5-del32 allele genotype affects the vertical transmission of HIV-1, or whether it affects disease progression [6,16,20-22]. One meta-analysis has revealed that perinatal infection is not significantly altered by heterozygosity for CCR5-del32 in children [23]. Another metaanalysis has been performed among 10 studies including 1317 HIV-1 infected children, addressing the effects of CCR5del32. For progression to clinical AIDS, CCR5-del32 showed an overall non-significant trend for protection (hazard ratio 0.84, 95\% confidence interval 0.58-1.23).

However, survival analyses showed a statistically significant time-dependence. The CCR5-del32 genotype was associated with a decreased risk of death among perinatally infected children, although only during the first years of life [21].

Multiple factors may affect HIV-1 disease progression in perinatally infected children, such factors include in utero versus intrapartum infection, maternal disease status at the time of delivery [24], therapeutic and prophylactic treatment of the mother and infant, and host human leucocyte antigen (HLA) genotype 11. In our studied population, the CCR5 genotype was unable to account for the difference in pattern of disease progression among the three groups (rapid, moderate and slow progressors). However, we can not exclude a potential role for these genetic characteristics, since sample size in our study was limited, and the allele frequency of CCR5del32 was too low to allow statistical comparisons with adequate resolving power. Studies with larger populations may further elucidate the role of this allele and other host factors in the regulation of HIV-1 pathogenesis in children.

\section{Ackowledgments}

The authors thank the staff of the IMT-SP and the CEADIPe-UNIFESP for technical assistance.

\section{References}

1. Ministério da Saúde. Programa de DST/AIDS. Guia de tratamento clínico da infecção pelo HIV em crianças. Brasília, 2004.

2. Hermione Lyall E.G. Paediatric HIV in 2002: a treatable and preventable infection. J Clin Virol 2002;25(2):107-19.

3. De Rossi A., Masiero S., Giaquinto C., et al. Dynamics of viral replication in infants with vertically acquired human immunodeficiency virus type 1 infection. J Clin Invest 1996;97(2):323-30.

4. Adams D.H., Lloyd A.R. Chemokines: leucocyte recruitment and activation cytokines. Lancet 1997;349(9050):490-5.

5. Carrington M., Kissner T., Gerrard B., et al. Novel alleles of the chemokine-receptor gene CCR5. Am J Hum Genet. 1997;61(6):1261-7.

6. Dean M., Carrington M., Winkler C., et al. Genetic restriction of HIV-1 infection and progression to AIDS by a deletion allele of the CKR5 structural gene. Hemophilia Growth and Development Study, Multicenter AIDS Cohort Study, Multicenter Hemophilia Cohort Study, San Francisco City Cohort, ALIVE Study. Science 1996;273(5283):1856-62. Erratum in: Science 1996;274(5290):1069.

7. Mummidi S., Ahuja S.S., McDaniel B.L., Ahuja S.K. The human CC chemokine receptor 5 (CCR5) gene. Multiple transcripts with 5 '-end heterogeneity, dual promoter usage, and evidence for polymorphisms within the regulatory regions and noncoding exons. J Biol Chem 1997;272(49):30662-71. 
Table 1. Demographic and clinical characteristics of the study population

\begin{tabular}{lcc}
\hline Total number of individuals $(\mathrm{N})$ & 51 & \\
Gender Female & $32(63 \%)$ & \\
Median age (range) & $9(3-16)$ & \\
Median CD 4 count (range) & $842(20-1735)$ & \\
Median count $\mathrm{CD}_{4}$ nadir & $432(3-1613)$ & \\
Clinical category* & $\mathrm{N}$ & $\%$ \\
$\mathrm{~A}$ & 9 & 18 \\
$\mathrm{~B}$ & 20 & 39 \\
$\mathrm{C}$ & 19 & 37 \\
$\mathrm{~N}$ & 3 & 6 \\
Immunological category* & & \\
1 & 9 & 18 \\
2 & 19 & 39 \\
3 & 21 & 43 \\
\hline
\end{tabular}

*Centers for Disease Control [9].
Figure 1. CCR5 genotypes among HIV-1 infected children. Lanes 1, 2, 3 and 5 represent the PCR products from samples with the homozygous wild-type genotype (fragments of $189 \mathrm{pb} / \mathrm{wt} / \mathrm{wt})$. Lanes 4 and 6 represent the PCR products from 2 samples heterozygous for the del32 genotype (with the presence of both fragments of 189 and 157bp/ wt/del32).

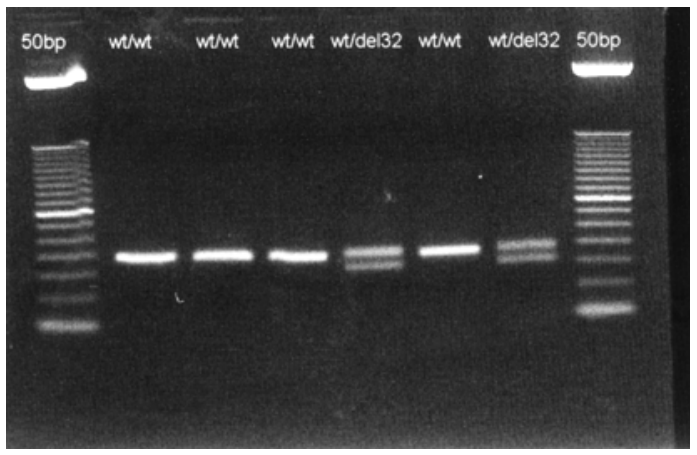

Table 2. Incidence of CCR5 genotypes among HIV-1 infected children according to the pattern of progression to AIDS

\begin{tabular}{lccc}
\hline & \multicolumn{3}{c}{ Type of progression to AIDS } \\
\cline { 2 - 4 } CCR5 genotype & Rapid & Moderate & Slow \\
\hline Homozygous wild type (wt/wt) & 17 & 27 & 5 \\
Heterozygous (del32/wt) & 1 & 1 & 0 \\
Homozygous mutant (del32/del32) & 0 & 0 & 0 \\
Total number of cases & 18 & 28 & 5 \\
\hline
\end{tabular}

8. Centers for Disease Control - 1994. Revised classification system for human immunodeficiency virus (HIV) infection in children less than 13 years of age. MMWR 1994;43:1-10.

9. Huang Y., Paxton W.A., Wolinsky S.M., et al. The role of a mutant CCR5 allele in HIV-1 transmission and disease progression. Nat Med 1996;2(11):1240-3.

10. Michael N.L., Louie L.G., Rohrbaugh A.L., et al. The role of CCR5 and CCR2 polymorphisms in HIV-1 transmission and disease progression. Nat Med 1997;3(10):1160-2.

11. Sheppard H.W., Celum C., Michael N.L., et al. HIV-1 infection in individuals with the CCR5-Delta32/Delta32 genotype: acquisition of syncytium-inducing virus at seroconversion. J Acquir Immune Defic Syndr 2002;29(3):307-13.

12. Just J.J., Abrams E., Louie L.G., et al. Influence of host genotype on progression to acquired immunodeficiency syndrome among children infected with human immunodeficiency virus type 1 . J Pediatr 1995;127(4):544-9.

13. Misrahi M., Teglas J.P., N'Go N., et al. CCR5 chemokine receptor variant in HIV-1 mother-to-child transmission and disease progression in children. French Pediatric HIV Infection Study Group. JAMA 1998;279(4):277-80.

14. Samson M., Libert F., Doranz B.J., et al. Resistance to HIV-1 infection in caucasian individuals bearing mutant alleles of the CCR-5 chemokine receptor gene. Nature 1996;382(6593):722-5.

15. Zimmerman P.A., Buckler-White A., Alkhatib G., et al. Inherited resistance to HIV-1 conferred by an inactivating mutation in CC chemokine receptor 5: studies in populations with contrasting clinical phenotypes, defined racial background, and quantified risk. Mol Med 1997;3(1):23-36.

16. McNicholl J.M., Smith D.K., Qari S.H., Hodge T. Host genes and HIV: the role of the chemokine receptor gene CCR5 and its allele. Emerg Infect Dis 1997;3(3):261-71. Review. Erratum in: Emerg Infect Dis 1997;3(4):584.
17. Martinson J.J., Chapman N.H., Rees D.C., et al. Global distribution of the CCR5 gene 32-basepair deletion. Nat Genet 1997;16(1):100-3.

18. Silva M.C., Rossini M.A, Sabino E.C., et al. Prevalence of deletion in the â-chemokines receptores (D32CCR5) sequency codificator in blood donors in Sao Paulo City (Brazil).[Abstract 11123].In Program and abstracts: 12th International AIDS Conference, Geneva, Switzerland, 1998.

19. Chies J.A., Hutz M.H. High frequency of the CCR5delta32 variant among individuals from an admixed Brazilian population with sickle cell anemia. Braz J Med Biol Res 2003;36(1):71-5. Epub 2002;19.

20. Contopoulos-Ioannidis D.G., O’Brien T.R., Goedert J.J., et al. Effect of CCR5-delta32 heterozygosity on the risk of perinatal HIV-1 infection: a meta-analysis. J Acquir Immune Defic Syndr. 2003;32(1):70-6. Erratum in: J Acquir Immune Defic Syndr 2003;32(5):575.

21. Ioannidis J.P., Contopoulos-Ioannidis D.G., Rosenberg P.S., et al. Effects of CCR5-delta32 and CCR2-64I alleles on disease progression of perinatally HIV-1-infected children: an international meta-analysis. AIDS 2003;17(11):1631-8.

22. Liu R., Paxton W.A., Choe S., et al. Homozygous defect in HIV-1 coreceptor accounts for resistance of some multiply-exposed individuals to HIV-1 infection. Cell 1996;86(3):367-77.

23. Rousseau C.M., Just J.J., Abrams E.J., et al. CCR5del32 in perinatal HIV-1 infection. J Acquir Immune Defic Syndr Hum Retrovirol 1997;16(4):239-42.

24. Blanche S., Mayaux M.J., Rouzioux C., et al. Relation of the course of HIV infection in children to the severity of the disease in their mothers at delivery. $\mathrm{N}$ Engl J Med 1994;330(5):308-12. 